\title{
DIGESTING AMPAS BAUKSIT UNTUK PEMBUATAN TAWAS SKALA PILOT
}

\author{
Digesting Bauxite Tailings for Alum Manufacture at Pilot Scale
}

\author{
KUKUH N. HIDAYAT, HUSAINI dan SUGANAL \\ Puslitbang Teknologi Mineral dan Batubara \\ Jalan Jenderal Sudirman 623 Bandung 40211 \\ Telp. (022) 6030483, Fax. (022) 6003373 \\ e-mail: kukuhnoer@gmail.com
}

\begin{abstract}
ABSTRAK
Limbah atau ampas bauksit hasil pencucian belum termanfaatkan dengan optimal dan hanya menimbulkan pencemaran lingkungan, padahal kandungan berharga yang ada di dalamnya seperti alumina masih bisa diolah menjadi koagulan (tawas atau PAC). Tawas dapat dihasilkan melalui proses digesting bauksit dengan menggunakan asam sulfat. Percobaan pembuatan tawas ini menggunakan ampas pencucian bauksit asal Meliau, Kalimantan Barat, berupa undersize rotary drum scrubber (RDS) yang berukuran +60 mesh dan sudah mengalami penggerusan sampai -150 mesh. Tujuan penelitian ini adalah untuk mendapatkan kondisi optimum proses pembuatan tawas skala pilot. Proses ini dimulai dengan proses reduksi bauksit dengan ball mill, dilanjutkan dengan pelarutan bauksit dengan asam sulfat dalam sebuah reaktor pada suhu $100{ }^{\circ} \mathrm{C}$. Filtrat yang dihasilkan direduksi kandungan besinya dengan diuapkan, sehingga menjadi tawas. Setelah dilakukan optimasi pembuatan tawas, kondisi terbaik yang diperoleh pada pembuatan tawas dari ampas adalah untuk berat ampas sebesar $50 \mathrm{~kg}$ dibutuhkan asam sulfat sebesar 120,89 kg dan air 3,62 kg yang menghasilkan persen ekstraksi $\mathrm{Al}_{2} \mathrm{O}_{3} 98,62 \%$ pada kondisi suhu $100^{\circ} \mathrm{C}$, dengan waktu 1 jam.
\end{abstract}

Kata kunci: Ampas bauksit, koagulan, digesting, tawas, skala pilot.

\begin{abstract}
Waste or washed bauxite tailling is unoptimally used and causes environtmental pollution, meanwhile the valuable contents like alumina can be processed into coagulant (alum or PAC). Alum can be produced by bauxite digesting process with sulfuric acid. The research on making alum was conducted using washed bauxite tailling from Meliau, West Kalimantan, undersize of rotary drum scrubber (RDS) sized +60 mesh and already milling up -150 mesh. The purpose of this research is to get an optimum condition of alum production process at pilot scale. This process strarted from bauxite reduction with ball mill, then it was solved with sulfuric acid in a reactor at temperature of $100^{\circ} \mathrm{C}$. The iron content of the filtrate was then reducted by steam to produce alum. After establishing condition process optimization of the alum production, it resulted the best condition process for $50 \mathrm{~kg}$ bauxite tailing, 120,89 $\mathrm{kg}$ of sulfuric acid and 3,62 $\mathrm{kg}$ of water were needed which yielded $98,62 \% \mathrm{Al}_{2} \mathrm{O}_{3}$ extraction at $100^{\circ} \mathrm{C}$ for 1 hour.
\end{abstract}

Keywords: Bauxite tailing, coagulant, digesting, alum, pilot scale.

\section{PENDAHULUAN}

Bauksit merupakan bahan yang heterogen, mempunyai mineral dengan susunan utama oksida aluminium, yaitu berupa mineral buhmit $\left(\mathrm{Al}_{2} \mathrm{O}_{3} \mathrm{H}_{2} \mathrm{O}\right)$ dan mineral gibsit $\left(\mathrm{Al}_{2} \mathrm{O}_{3} .3 \mathrm{H}_{2} \mathrm{O}\right)$ (Indian Bureau of Mines, 2016). Secara umum bauksit mengandung $45-65 \%$ $\mathrm{Al}_{2} \mathrm{O}_{3}, 1-12 \% \quad \mathrm{SiO}_{2}, 2-25 \% \mathrm{Fe}_{2} \mathrm{O}_{3}$, $\mathrm{TiO}_{2}>3 \%$, dan $14-36 \% \mathrm{H}_{2} \mathrm{O}$ (Husaini dkk., 
2013). Pengolahan bauksit di Indonesia telah dilakukan oleh PT. ANTAM Tbk, dalam perkembangannya dimulai di daerah Kijang Pulau Bintan yang telah ditutup pada 2009 dan kemudian dikembangkan di wilayah Tayan, Kalimantan Barat. Problem yang muncul dalam pengolahan bauksit ini adalah ampasnya yang belum dimanfaatkan secara maksimal sehingga akan menjadi limbah yang berbahaya bagi lingkungan. Sedangkan kandungan aluminium yang ada dalam ampas masih ada, oleh karena itu perlu dilakukan penelitian dalam pemanfaatan ampas bauksit ini guna peningkatan nilai tambah sesuai Peraturan Menteri Energi dan Sumberdaya Mineral, salah satunya adalah pembuatan tawas sebagai koagulan (Husaini dkk., 2011). Tawas (aluminium sulfat) diproduksi melalui tahap proses yang sederhana dari aluminium trihidrat dan asam sulfat (Etuaful, 2013) menurut reaksi sebagai berikut:

$$
\begin{aligned}
& 2 \mathrm{Al}(\mathrm{OH})_{3}+3 \mathrm{H}_{2} \mathrm{SO}_{4}+8 \mathrm{H}_{2} \mathrm{O} \\
& \rightarrow \mathrm{Al}_{2}\left(\mathrm{SO}_{4}\right)_{3} .14 \mathrm{H}_{2} \mathrm{O} \Delta \mathrm{fH}=-156 \mathrm{~kJ} \mathrm{~mol}^{-1} \text {. (1) }
\end{aligned}
$$

Dalam produksi tawas, lumpur yang dihasilkan masih dalam keadaan asam dan apabila dibuang tidak akan menyebabkan kerusakan lingkungan terutama kehidupan air (Barrios-Perez, 2003).

Pemberian larutan tawas (koagulan) pada pengolahan air baku dimaksudkan untuk menyatukan bahan-bahan koloid yang larut dalam air menjadi gumpalan yang lebih besar yang disebut flok. Koagulan yang bermuatan positif akan mengikat butiran koloid yang bermuatan negatif yang cukup besar sehingga mudah diendapkan (Haslindah dan Zulkifli, 2012). Koagulasi dan flokulasi terjadi secara berurutan, yang memungkinkan menimbulkan tabrakan partikel dan pertumbuhan flok. Hal ini kemudian diikuti oleh sedimentasi (Prakash, Sockan dan Jayakaran, 2014). Masih belum banyak penelitian tentang pemanfaatan ampas dari bauksit ini. Penelitian untuk pembuatan tawas rata-rata memanfaatkan limbah rumah tangga yang masih mengandung aluminium (Kartika, 2014).

Melihat kegunaan tawas yang dikenal sebagai flocculator yang berfungsi untuk menggumpalkan kotoran-kotoran pada proses penjernihan, kekeruhan dalam air dapat dihilangkan melalui penambahan sejenis bahan kimia yang disebut koagulan (Pratiwi, Sunarsih dan Windi, 2012). Karena itu diperlukan pengembangan penelitian tawas ini untuk skala yang lebih besar (skala pilot) sehingga diharapkan hasilnya juga dapat dikomersialkan.

Pada penelitian ini dilakukan proses ekstraksi alumina yang terdapat pada bijih bauksit, dilarutkan dengan larutan soda api atau kaustik soda dengan konsentrasi dan suhu tertentu. Reaksi yang terjadi adalah :

$\mathrm{Al}_{2} \mathrm{O}_{3} 3 \mathrm{H}_{2} \mathrm{O}+2 \mathrm{NaOH} \rightarrow 2 \mathrm{NaAlO}_{2}+4 \mathrm{H}_{2} \mathrm{O}(2)$

Reaksi kimia yang terjadi antara aluminium oksida pada bauksit dengan asam sulfat adalah sebagai berikut:

$$
\begin{array}{r}
\mathrm{Al}_{2} \mathrm{O}_{3}+3 \mathrm{H}_{2} \mathrm{SO}_{4} \rightarrow \mathrm{Al}_{2}\left(\mathrm{SO}_{4}\right)_{3}+3 \mathrm{H}_{2} \mathrm{O} \\
\Delta \mathrm{G}_{0}=-147,17 \mathrm{kkal} / \mathrm{mol} \ldots \ldots \ldots . . . . . \\
\mathrm{Fe}_{2} \mathrm{O}_{3}+3 \mathrm{H}_{2} \mathrm{SO}_{4} \rightarrow \mathrm{Fe}_{2}\left(\mathrm{SO}_{4}\right)_{3}+3 \mathrm{H}_{2} \mathrm{O} \\
\Delta \mathrm{G}_{0}=-138,75 \mathrm{kkal} / \mathrm{mol} \ldots \ldots \ldots . . . . . .
\end{array}
$$

Energi bebas pembentukan larutan pada kondisi standar $\left(25^{\circ} \mathrm{C}\right)$ dari kedua persamaan reaksi di atas adalah negatif. Ini menunjukkan bahwa reaksi kimia tersebut adalah eksoterm (menghasilkan panas).Terjadinya panas pada reaksi eksoterm ini menguntungkan, karena panas yang diperlukan untuk mempertahankan suhu reaksi pada suhu $100^{\circ} \mathrm{C}$ dapat dihemat, bahkan dapat dibantu oleh panas pelarutan asam sulfat dengan air yang juga bersifat eksoterm. Makin negatif nilai $\Delta \mathrm{Go}$-nya, semakin mudah reaksinya.

Tujuan dari penelitian ini adalah untuk mendapatkan parameter optimum proses digesting ampas bauksit untuk pembuatan tawas pada skala pilot.

\section{METODE}

Alur pembuatan tawas skala pilot dapat dilihat pada Gambar 1. 


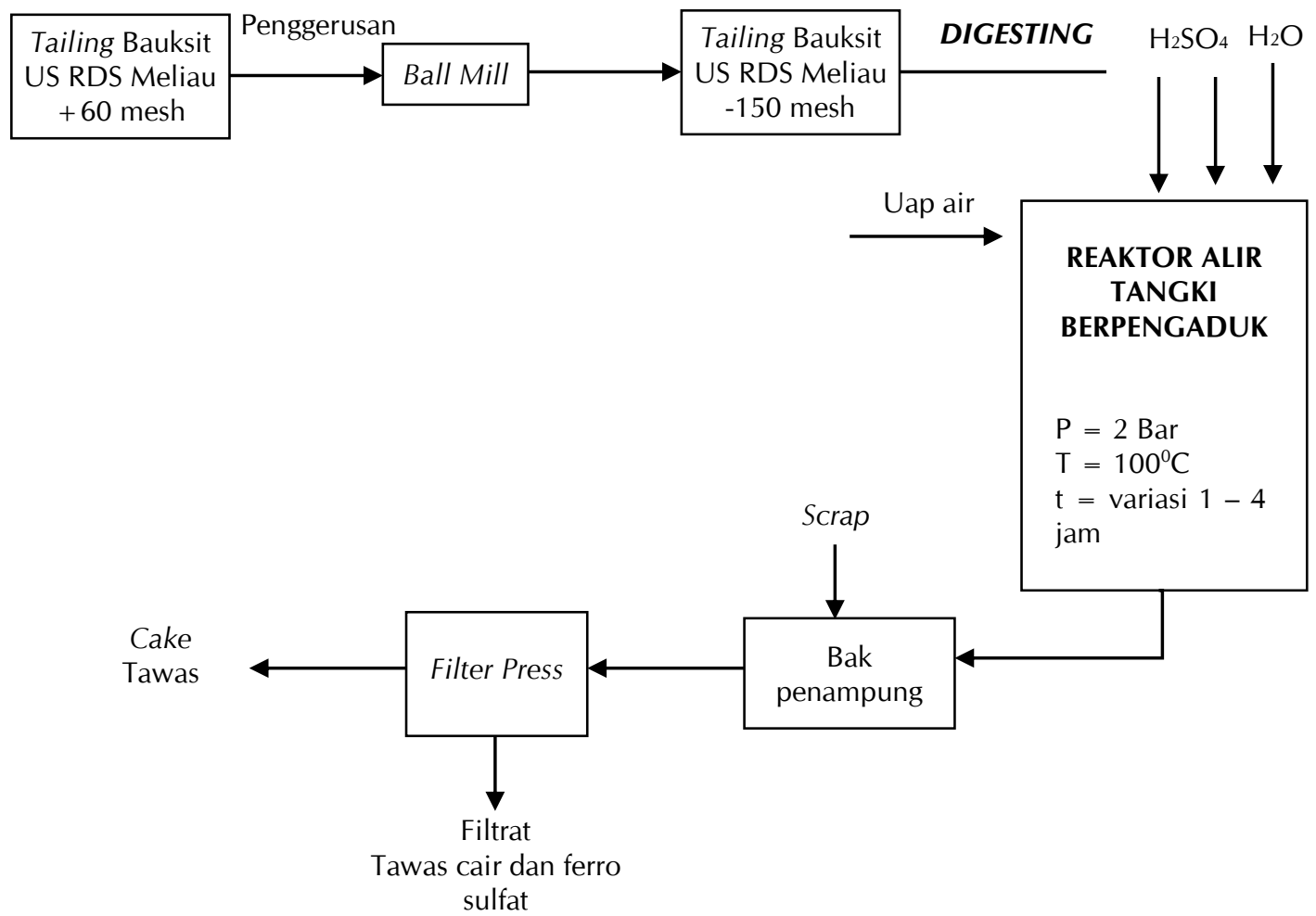

Gambar 1. Bagan alir proses digesting ampas bauksit untuk pembuatan tawas

Percobaan pembuatan tawas ini menggunakan ampas pencucian bauksit asal Meliau, Kalimantan Barat, berupa undersizerotary drum scrubber (RDS) yang berukuran $-2 \mathrm{~mm}+60$ mesh dan sudah mengalami penggerusan sampai -150 mesh sebanyak $50 \mathrm{~kg}$ berat kering. Peralatan yang digunakan adalah reaktor, filter press dan ball mill. Sumber panas yang digunakan adalah uap air (steam) berasal dari boiler dengan tekanan 2 bar. Percobaan dilakukan sebanyak 3 (tiga) kali dengan memvariasikan waktu reaksi (1 sampai 4 jam) dan ekses $\mathrm{H}_{2} \mathrm{SO}_{4} \quad(0 \%$ dan $+5 \%$ dari stoikiometri). Kondisi proses yang dijaga tetap adalah suhu sluri $100^{\circ} \mathrm{C}$ dan persen padatan $25 \%$. Percontoh sluri hasil reaksi diambil setiap jam untuk mengetahui banyaknya alumina yang sudah bereaksi dengan asam sulfat. Dari percobaan ini, persen ekstraksi $\mathrm{Al}_{2} \mathrm{O}_{3}$ yang dicapai untuk selang waktu reaksi antara 1 sampai 4 jam berkisar antara 96,02 $98,88 \%$. Dalam waktu 1 jam reaksi sudah mencapai persen ekstraksi $\mathrm{Al}_{2} \mathrm{O}_{3}$ tinggi yaitu sekitar 97\%. Dengan demikian, kondisi optimum proses ekstraksi ampas bauksit dengan asam sulfat pada suhu $100^{\circ} \mathrm{C}$ ini cukup 1 jam. Oleh karena itu, percobaan berikutnya cukup dilakukan dengan waktu reaksi 1 jam.
Percobaan lanjutan ini dilakukan dengan memvariasikan ekses asam sulfat seperti pada percobaan sebelumnya yaitu $0 \%$ dan ekses $+5 \%$, sedangkan kondisi lainnya seperti persen padatan, suhu, ukuran partikel bauksit dijaga tetap. Dari percobaan ini, diperoleh persen ekstraksi alumina berkisar antara 98,60 $100 \%$. Semua hasil percobaan ini selanjutnya ditambah besi scrap untuk mereduksi kandungan ion feri menjadi fero, sehingga produk yang diharapkan adalah campuran aluminium sulfat dan fero sulfat. Keduanya merupakan koagulan yang paling cocok untuk penjernihan air limbah (Suherman dan Sumawijaya, 2013).

\section{HASIL DAN PEMBAHASAN}

Pada penelitian ini pembuatan tawas dilakukan dengan memvariasikan waktu reaksi, 1, 2, 3 dan 4 jam. Data hasil percobaan dapat dilihat pada Tabel 1 .

Waktu pelarutan sangat berpengaruh terhadap persen ekstraksi $\mathrm{Al}_{2} \mathrm{O}_{3}$ dan $\mathrm{Fe}_{2} \mathrm{O}_{3}$. Dari Tabel 1 dapat dilihat bahwa hasil \% ekstraksi dari variasi waktu dengan asam sulfat yang sama 
terlihat bahwa hasil optimum diperoleh pada saat waktu reaksi 1 jam, menghasilkan ekstraksi $\mathrm{Al}_{2} \mathrm{O}_{3}$ sebesar 97,02\%. Diambil waktu 1 jam karena melihat tren dari waktu berikutnya juga tidak terlalu menunjukkan hasil yang berbeda, dan jika dilihat pada waktu reaksi lebih dari 1 jam terjadi penurunan pada \% ekstraksi dari $\mathrm{Fe}_{2} \mathrm{O}_{3}$ meskipun \% ekstraksi $\mathrm{Al}_{2} \mathrm{O}_{3}$ tetap tinggi. Hal itu mengindikasikan bahwa kondisi optimum sudah tercapai pada saat waktu reaksi 1 jam.

Pada Gambar 2 dapat dilihat \% ektraksi $\mathrm{Al}_{2} \mathrm{O}_{3}$ tiap jam cenderung sama, yang berbeda dengan $\%$ ekstraksi $\mathrm{Fe}_{2} \mathrm{O}_{3}$ yang terlihat semakin menurun. Hal ini dapat terjadi karena waktu pelarutan alumina dengan asam ini berbeda-beda, tergantung dari karakteristik percontoh yang digunakan. Pada penelitian sebelumnya pada skala laboratorium diperoleh kondisi optimum adalah sekitar 50 menit, apabila lebih dari waktu tersebut persen ekstraksi tidak bertambah lagi atau cenderung tetap.

Tabel 2 menunjukkan variasi berat asam sulfat atau variasi ekses asam sulfat. Dari Tabel 2 dapat dilihat bahwa ekstraksi dari ketiga variasi ekses asam sulfat diperoleh hasil tertinggi pada saat ekses asam sulfat 0 atau $120,89 \mathrm{~kg}$, yaitu
$\%$ ekstraksi untuk $\mathrm{Al}_{2} \mathrm{O}_{3}$ sebesar 98,62\% dan $\mathrm{Fe}_{2} \mathrm{O}_{3}$ sebesar $49,38 \%$. Sedangkan pada ekses $+5 \%(126 \mathrm{~kg})$ terlihat penurunan pada persen ekstraksi. Hal ini mengindikasikan bahwa kondisi optimum sudah tercapai dan tidak efektif lagi apabila ekses asam sulfat ditambah ataupun dikurangi lagi. Hal ini disebabkan karena kondisi reaksi sudah jenuh.

Hasil \% ekstraksi tertinggi diperoleh pada saat ekses asam sulfat $120,89 \mathrm{~kg}$, yaitu \% ekstraksi untuk $\mathrm{Al}_{2} \mathrm{O}_{3}$ sebesar 97,54\% dan $\mathrm{Fe}_{2} \mathrm{O}_{3}$ sebesar $49,38 \%$. Dari grafik tersebut dapat dilihat juga bahwa penggunaan asam berlebih dapat meningkatkan persen ekstraksi meskipun pada persen ekstraksi $\mathrm{Fe}_{2} \mathrm{O}_{3}$ mengalami penurunan kemudian naik kembali pada penambahan ekses asam sulfat sebesar + 5\% (Gambar 3). Hal ini dapat terjadi karena dengan konsentrasi pelarut semakin tinggi, maka penurunan berat terlarut semakin besar sesuai dengan teori kinetika reaksi orde satu (Nnaji, Ani dan Ekwonu, 2013). Sama halnya dengan penelitian skala laboratorium yang telah dilakukan sebelumnya bahwa terjadinya perbedaan kondisi optimum yang diperoleh disebabkan percontoh yang digunakan memiliki karakteristik komposisi kimia yang berbedabeda (Husaini $d k k ., 2015$ ).

Tabel 1. Hasil percobaan pembuatan tawas dari ampas bauksit dengan variasi waktu reaksi

\begin{tabular}{|c|c|c|c|c|c|c|}
\hline \multirow{3}{*}{$\begin{array}{c}\text { No. } \\
\text { Percobaan }\end{array}$} & \multirow{3}{*}{$\begin{array}{c}\text { Bauksit } \\
(\mathrm{kg})\end{array}$} & \multirow{3}{*}{$\begin{array}{c}\text { Asam } \\
\text { Sulfat } \\
(\mathrm{kg})\end{array}$} & \multirow{3}{*}{$\begin{array}{l}\text { Waktu } \\
\text { (jam) }\end{array}$} & \multicolumn{3}{|c|}{ \% Ekstraksi } \\
\hline & & & & \multicolumn{2}{|c|}{$\mathrm{Al}_{2} \mathrm{O}_{3}$} & \multirow{2}{*}{$\mathrm{Fe}_{2} \mathrm{O}_{3}$} \\
\hline & & & & Umpan dan filtrat & Umpan dan residu & \\
\hline 1 & 50 & 120,89 & 1 & 56,66 & 97,02 & 71,69 \\
\hline 2 & 50 & 120,89 & 2 & 4,16 & 96,02 & 70,80 \\
\hline 3 & 50 & 120,89 & 3 & 14,05 & 96,51 & 63,94 \\
\hline 4 & 50 & 120,89 & 4 & 24,26 & 96,89 & 68,73 \\
\hline
\end{tabular}

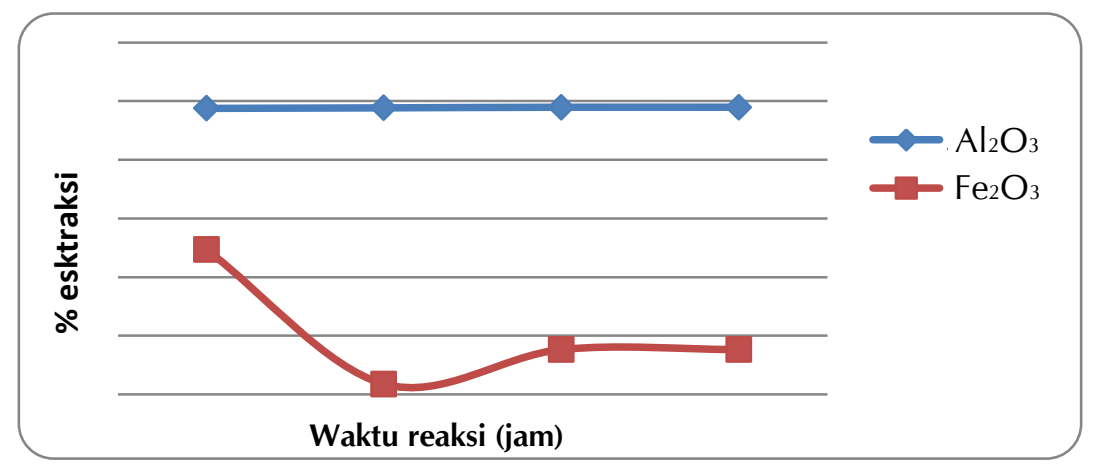

Gambar 2. Pengaruh waktu reaksi terhadap \% ekstraksi $\mathrm{Al}_{2} \mathrm{O}_{3}$ dan $\mathrm{Fe}_{2} \mathrm{O}$ 
Tabel 2. Hasil percobaan pembuatan tawas dari ampas bauksit dengan variasi ekses asam sulfat

\begin{tabular}{|c|c|c|c|c|c|c|}
\hline \multirow{3}{*}{$\begin{array}{c}\text { No. } \\
\text { Percobaan }\end{array}$} & \multirow{3}{*}{$\begin{array}{c}\text { Bauksit } \\
\text { (kg) }\end{array}$} & \multirow{3}{*}{ Ekses (\%) } & \multirow{3}{*}{$\begin{array}{c}\text { Asam } \\
\text { sulfat }(k g)\end{array}$} & \multicolumn{3}{|c|}{ \% Ekstraksi } \\
\hline & & & & \multicolumn{2}{|c|}{$\mathrm{Al}_{2} \mathrm{O}_{3}$} & \multirow[b]{2}{*}{$\mathrm{Fe}_{2} \mathrm{O}_{3}$} \\
\hline & & & & $\begin{array}{c}\text { Feed dan } \\
\text { filtrat }\end{array}$ & $\begin{array}{c}\text { Feed dan } \\
\text { residu }\end{array}$ & \\
\hline 1 & 50 & 0 & 120,89 & 64,03 & 98,62 & 49,38 \\
\hline 3 & 50 & +5 & 126,93 & 34,72 & 97,93 & 15,3 \\
\hline
\end{tabular}

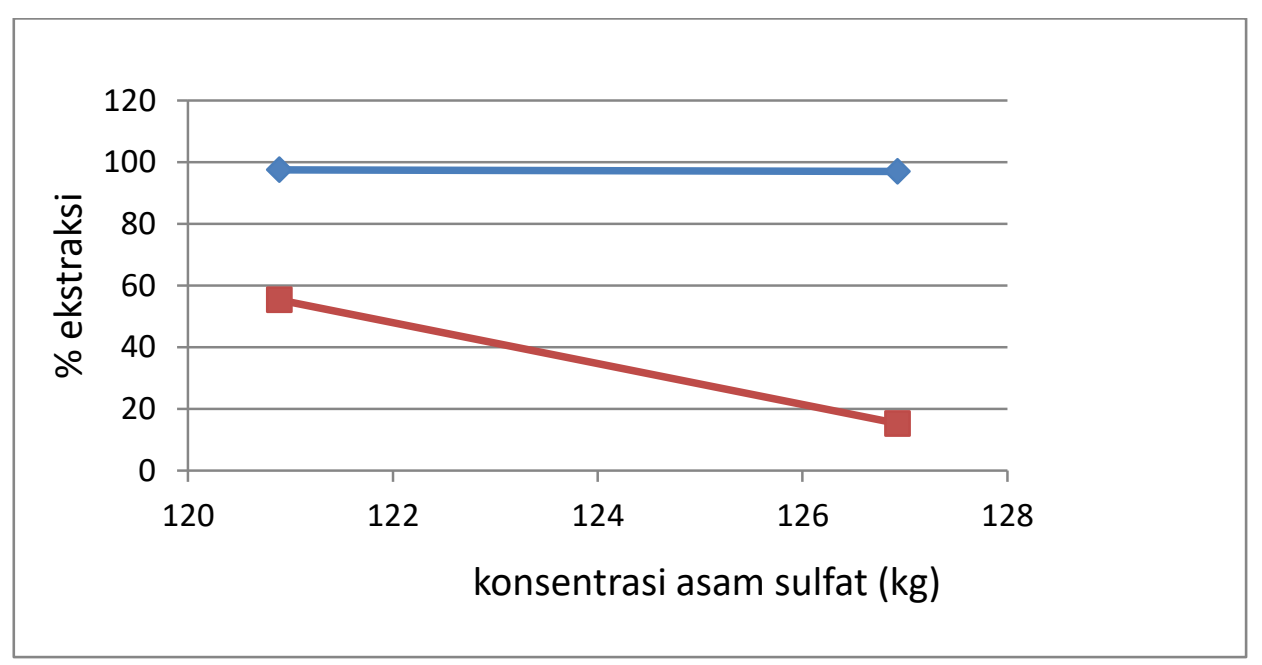

Gambar 3. Grafik pengaruh variasi ekses asam sulfat terhadap \% ekstraksi $\mathrm{Al}_{2} \mathrm{O}_{3}$ dan $\mathrm{Fe}_{2} \mathrm{O}_{3}$

Dari kedua hasil percobaan di atas dapat diketahui bahwa pengaruh waktu terhadap persen ekstraksi sangat berkaitan, yaitu semakin lama waktu pelarutan maka persen ekstraksi yang diperoleh semakin tinggi (Baldosano dkk., 2015), namun setelah mencapai kondisi yang optimum tidak dapat meningkatkan persen ekstraksi bahkan cenderung turun dilihat dari penurunan $\mathrm{Fe}_{2} \mathrm{O}_{3}$. Sama halnya dengan variasi ekses asam sulfat, untuk penambahan dan pengurangan juga tidak terlalu meningkatkan persen ekstraksi. Hasil yang sedikit berbeda diperoleh dengan penelitian sebelumnya, karena pada penelitian ini digunakan ampas bauksit dari Meliau, Kalimantan Barat sedangkan pada skala laboratorium menggunakan ampas dari Kijang, Pulau Bintan. Namun perbedaan hasil penelitian yang diperoleh tersebut tidak signifikan.

\section{KESIMPULAN}

Kondisi optimum proses digesting ampas bauksit dapat dicapai dengan kondisi parameter sebagai berikut: untuk berat ampas bauksit $50 \mathrm{~kg}$, diperlukan asam sulfat 120,89 $\mathrm{kg}$ dan air $3,62 \mathrm{~kg}$ pada suhu proses $100^{\circ} \mathrm{C}$ selama 1 jam yang menghasilkan ekstraksi $\mathrm{Al}_{2} \mathrm{O}_{3}$ sebesar $98,62 \%$. Selanjutnya dapat dilakukan uji pasar untuk dapat dikembangkan ke skala komersial.

\section{DAFTAR PUSTAKA}

Baldosano, H. Y., Beatriz, M., Castillo, M. G., Elloran, C. D. H. and Bacani, F. T. (2015) "Effect of particle size, solvent and extraction time on tannin extract from Spondias purpurea bark through Soxhlet extraction," Proceedings of the DLSU Research Congress, 3, pp. 4-9. Available at:

http://www.dlsu.edu.ph/conferences/dlsu res earch_congress/2015/proceedings/FNH/008F NH_Bacani_FT.pdf.

Barrios-Perez, J. (2003) Acid stabilization of sludge. Universidad Nacional Autonoma de Mexico.

Etuaful, R. K. (2013) Production of alum from bauxite waste from Awaso mine. Kwame Nkrumah University of Science and Technology, Kumasi-Ghana. Available at: 
http://ir.knust.edu.gh/bitstream/123456789/54 16/1/Buamah Rashid.pdf.

Haslindah, A. and Zulkifli (2012) "Analisis jumlah koagulan (tawas/AI2(SO4)3) yang digunakan dalam proses penjernihan air pada PDAM instalasi I Ratulangi Makassar," ILTEK, 7(13), p. 947.

Husaini, Aziz, M., Muta'alim, Yuhelda, Azhari, Pendi, S., Rustrendi, D., Wijaya, K., Gandamanah, I. and Sugandi, B. (2011) Aplikasi proses upgrading bauksit Tayan Kalimantan Barat dan pemanfaatan tailing pencuciannya untuk koagulan. Bandung: Puslitbang tekMIRA.

Husaini, Purnomo, H., Cahyono, S. S., Muta'alim, Soenara, T., Supriyanto, B. A., Wahyudi, A., Subiantoro, Sugandi, B., Pendi, S., Permana, A. S., Prakosa, A., Sudjarwo, Wijaya, K. and Widodo (2013) Peningkatan kadar dan pemrosesan bauksit bernilai tambah Kalimantan Barat serta pemanfaatan tailingnya. Bandung: Puslitbang tekMIRA.

Husaini, Purnomo, H., Suganal, Cahyono, S. S., Soenara, T., Supriyanto, B. A., Subiantoro, Azhari, Amalia, D., Sugiarti, S., Irfan, Ramanda, Y., Rahmat, Sugandhi, B., Dianawati, E. A., Permana, A. S., Pendi, S., Fatimah, T. S., Alamanda, N., Wijaya, K., Sulistyo, R. S. and Hidayat, A. T. (2015) Persiapan pembangunan demo plant rotary drum scrubber 50 ton/jam dan optimalisasi PAC dan tawas dari tailing washed bauksit. Bandung: Puslitbang tekMIRA.

Indian Bureau of Mines (2016) "Part-III: Mineral Reviews," in Indian Minerals Yearbook 2015. 54th Ed. Indian Bureau of Mines, pp. 4-1-415. Available at: https://ibm.gov.in/writereaddata/files/111820 16100421IMYB2015_Bauxite_17112016_Ad v.pdf.

Kartika, E. Y. (2014) "Pembuatan tawas," Jurnal Kimia Anorganik 2, pp. 1-7. Available at: https://anzdoc.com/jurnal-kimia-anorganik-226-maret-2014-pembuatan-tawas-eka-y.html.

Nnaji, N. J., Ani, J. U. and Ekwonu, A. M. (2013) "The solution of reversible first order reaction equation revisited," Acta Chimica \& Pharmaceutica Indica, 3(3), pp. 201-2011. Available at:

https://www.tsijournals.com/abstract/thesolution-of-reversible-first-order-reactionequation-revisited-11266. html.

Prakash, N. B., Sockan, V. and Jayakaran, P. (2014) "Waste water treatment by coagulation and flocculation," International Journal of Engineering Sciences and Innovative Technology, 3(2), pp. 479-484. Available at: http://www.ijesit.com/Volume 3/Issue 2/IJESIT201402_61.pdf.

Pratiwi, Y., Sunarsih, S. and Windi, W. F. (2012) "Uji toksisitas limbah cair laundry sebelum dan sesudah diolah dengan tawas dan karbon aktif terhadap bioindikator (Cyprinuscarpio L)," in Prosiding Seminar Nasional Aplikasi Sains \& Teknologi (SNAST) Periode III. Yogyakarta: IST AKPRIND, p. A-298-A-306. Available at: http://repository.akprind.ac.id/sites/files/confer ence-proceedings/2012/pratiwi_14379.pdf.

Suherman, D. and Sumawijaya, N. (2013) "Menghilangkan warna dan zat organik air gambut dengan metode koagulasi-flokulasi suasana basa," Jurnal RISET Geologi dan Pertambangan, 23(2), pp. 127-139. doi: 10.14203/risetgeotam2013.v23.75. 